\title{
Case Report and Review of the Literature
}

\section{Giant Tumors of the Breast in Adolescence: Clinical Algorithm for Reconstruction of Young Patients in Thelarche}

\author{
Kern $P^{1,2^{*}}$, Ramachandramoorthy $V^{2}$, Bittner $A K^{1}$, Rezai $M^{3}$, Kimmig $R^{1}$ and Hoffmann $O^{1}$ \\ ${ }^{I}$ University Hospital of Essen, Women's Department, National Center of Tumor Diseases (NCT), Essen, Germany \\ ${ }^{2}$ St. Elisabeth-Hospital, Women's Department, Ruhr-University of Bochum, Bochum, Germany \\ ${ }^{3}$ European Breast Center- Dr. Rezai, St. Anna Hospital, Duisburg, Germany
}

\section{A R T ICLE INFO \\ Article history: \\ Received: 2 December, 2021 \\ Accepted: 20 December, 2021 \\ Published: 31 December, 2021 \\ Keywords: \\ Giant breast tumors \\ adolescence \\ thelarche \\ PASH tumors \\ fibroadenoma \\ cystosarcoma phylloides}

reconstruction

\begin{abstract}
A B S T R A C T
Introduction: Breast tumors such as cystosarcoma phylloides and fibroadenoma may show rapid growth and occur early in thelarche. In adolescents, tumor growth often remains unnoticed due to a lack of breast awareness or a sense of shame in these young girls. The necessity for surgical intervention may interfere with the normal development of the breast, however in certain cases has to be performed due to the threat of deformation of the growing breast or the malignant potential of some tumors like cystosarcoma phylloides. However, visible scars have to be avoided at any price in these young girls, as they are still in their pre-marital and psychologically vulnerable phase. The presumed size of the breast after completion of all Tanner stages of breast development has to be taken into consideration while planning the immediate or deferred reconstruction.

Methods: We report on three young girls, 13, 14 and 16 years of age, who presented with a giant cystosarcoma phylloides of 9,6 cm (190 grams), a giant fibroadenoma of $14 \mathrm{~cm}$ (287 grams) and a giant PASH-tumor of $16,3 \mathrm{~cm}$ (957 grams). All patients were in their thelarche. The extension of the tumor was almost to the whole circumference of the breast with close borders to the skin en velope, resulting in a marked anisomastia due to the giant tumor size. We are proposing here scar-sparing procedures adapted to the form of the breast and the BMI of the patients. For access to the tumor, in two cases, we chose the anterior axillary line to avoid visible scars on the surface of the breast - one with autologous and one with heterologous, implant-based reconstruction. In the third case, the patient had a marked anisomastia with a massively ptotic breast with a huge broadening of the nipple-areolar-complex due to the growth of the tumor. Here we selected a tumor-size adapted, inferior-pedicled reduction mammaplasty according to Ribeiro in the modification of Rezai with a skin reduction and shortening of the diameter of the areola. Patient reportedoutcome has been measured by validated Breast-Q-questionnaires.

Results: We present three different types of access for the removal of giant tumors and three options for the reconstruction of patients in their thelarche. Two tumors were removed through axillary access to the breast to avoid scars in the developing breast. We achieved free margins at first surgical intervention in all three cases. One reconstruction was performed by autologous tissue through lateral thoracic wall advancement mammaplasty. Another patient had an implant-based reconstruction. The third patient - who presented with a macromastia with marked enlargement of the nipple-areola-complex was treated with a tumor-adapted reduction mammaplasty. All three young patients have reported a high degree of satisfaction in validated Breast QoL questionnaires with the outcome of the procedures.
\end{abstract}

(C) 2021 Kern P. Hosting by Science Repository. 


\section{Introduction}

Breast tumors in adolescence usually present as simple fibroadenoma at a size of $3 \mathrm{~cm}$ and - when occurring with other soft tissue masses - may be associated with inherited syndromes [1]. In some case cohort studies common fibroadenoma measure up to 0,9 up to $9,1 \mathrm{~cm}$, whereas juvenile fibroadenoma and phyllodes tumors may have an extension of 1,7 to 12,5 $\mathrm{cm}$ [2]. Breast masses in adolescence generally occur in $3,2 \%$. Whereas common and juvenile tumors are always benign lesions, phyllodes tumors have a $10 \%$ chance to be malignant [3].

There is ample evidence that tumors with rapid growth like fibroadenoma have to be excised, even when they are not malignant, because the longer surgery is postponed, the less residual normal breast tissue is available for reconstruction. High-volume institutions like Johns Hopkins University recommend excision of the phyllodes tumors with clear margins after confirmation through core biopsy to avoid recurrence, and in cases of large disease, their published guidelines say that mastectomy may be required [4]. However, it is well known that mastectomy may be detrimental to psychological health in breast cancer and that immediate reconstruction has a significantly better impact on psychological well-being than deferred than no reconstruction [5]. These data have been accrued in adult women who have a marital status or a stable partnership. It is even more likely that adolescents who do not have completed their breast development, have markedly more psychological problems with a removed breast or visible scars on the surface of the breast.

\section{Patients and Methods}

We demonstrate three different types of benign breast tumors and show how mastectomy can safely be avoided and almost non-visible scars may be achieved minimizing the psychological trauma of extensive surgery of the breast in adolescence: i. One patient of 13 years of age presented with a giant cystosarcoma phylloides of 9,6 cm (190 grams) in her right breast. Breast size: unaffected breast: B cup, affected breast: E cup.

ii. Another patient of 14 years of age presented with a giant PASHtumor of $16,3 \mathrm{~cm}$ ( 957 grams) also in her right breast. Breast size: unaffected breast: B cup, affected breast: E cup.

iii. A third patient of 16 years presented with a juvenile fibroadenome of $14 \mathrm{~cm}$ (287 grams) in her left breast with a marked macromastia and anisomastia. Breast size: unaffected breast: B cup, affected breast: D cup.

All patients were in their thelarche with the extension of the tumor to the whole circumference of the breast with direct contact of the tumor to the skin envelope, causing a marked anisomastia due to the tumor size. Surgical removal of the tumor was monitored by intraoperative ultrasound with a sterile ultrasound probe to achieve clear margins and to preserve healthy breast tissue wherever it was deemed possible.

\section{Results}

\section{Anterior Axillary Line Approach: Heterologous, Implant- Based Reconstruction}

The first type of tumor removal and reconstruction with a non-visible scar was in the case of 13-year-old girl with a giant breast tumor of 957 grams/Cup E (Figure 1a). Contralateral breast size was Cup A. Although the whole breast was totally filled up with tumor tissue, breast conservation was ultimately desired by the young patient and her parents. We chose a non-visible approach at the lateral breast base (Figure 1b) and resected the huge tumor with free margins (Figure 1c). Simultaneous reconstruction of the empty skin envelope (Figure 1d) was performed with a $250 \mathrm{cc}$ cohesive gel implant which was adapted to the actual size of the breast. It was destined to be changed to the final size of the breast when thelarche had been completed.
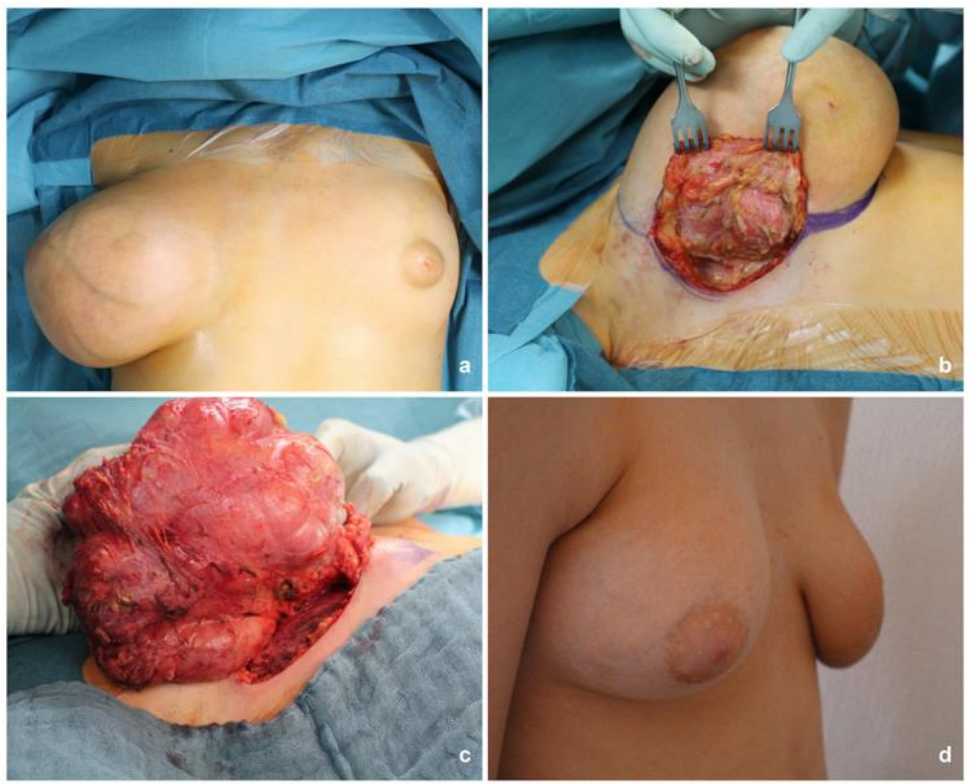

Figure 1: Giant breast tumor, 13-year-old girl: a) anisomastia due to the extraordinary size of the PASH tumor. b) Anterior axillary line approach to glandula. c) Removal of a PASH tumor of 957 gram with free margins. d) Post-operative result after implant reconstruction. 


\section{Anterior Axillary Approach/Autologous Reconstruction (Lateral Advancement Mammaplasty)}

The second type of tumor removal and reconstruction with a non-visible scar was in the case of 14-years old girl with a breast tumor of 190
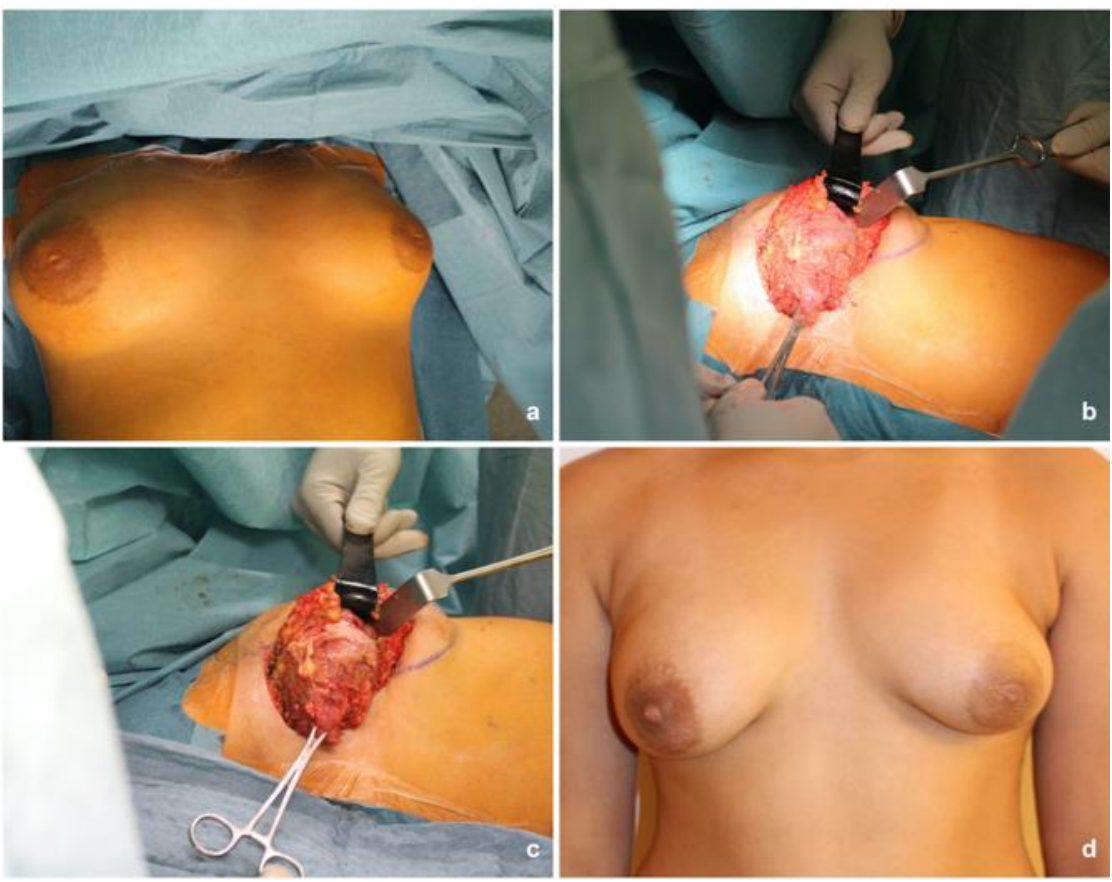

Figure 2: Giant breast tumor, 14 year-old girl: a) anisomastia due to the giant breast tumor. b) Access to the tumor at the anterior axillar line. c) Removal of a 190 grams fibroadenoma. d) Postoperative result after reconstruction with autologous tissue (fat from the latissimus dorsi region / lateral advancement mammaplasty according to Rezai).

The preparation of the tumor from the skin was monitored by intraoperative ultrasound to achieve free margins and to preserve healthy breast tissue. Sufficient pedicled fat tissue was harvested to refill the skin envelope of the right breast from the musculus latissimus dorsi region without the muscle itself. Post-reconstruction results did not reveal any scar from the front view and provided symmetry as aesthetic outcome (Figure 2d). Nipple-areolar necrosis did not occur in spite of the considerable size of the tumor and preparation close to the skin.

\section{Wise Pattern Approach - Autologous Tissue Based Reconstruction (Reduction Mammaplasty According to Ribeiro)}

The third type of tumor removal and reconstruction was performed in a case of a 16-year-old girl with a large breast tumor causing marked ptosis of the left breast with massive enlargement of the nipple-areolacomplex. The size of the biopsy-proven juvenile fibroadenoma was $14 \mathrm{x}$ $9,2 \times 3,8 \mathrm{~cm}$, filling the whole extension of the breast (Cup D size), while the contralateral side was a Cup B size (Figure 3a). Due to the ptosis, we chose as technique a reduction mammaplasty pattern according to Ribeiro in the modification of Rezai (inverted T-incision, inferiorpedicled) (Figure 3b) and removed a large tumor of 287 grams with free margins (Figure 3c). As immediate breast reconstruction, we rearranged the autologous remaining tissue and formed a Cup B breast (Figure 3d).
grams/Cup C (Figure 2a). Contralateral breast size was Cup B. Almost the whole breast was filled by the tumor and optimal breast shape was desired by the patient after surgery. We chose a non-visible approach at the lateral breast base / anterior axillary line (Figure 2b) and removed a fibroadenoma of 190 grams (Figure 2c).

\section{Clinical Algorithm - Tumor Resection and Reconstruction}

As a surgical approach, we chose in two cases a non-visible approach to the mammary gland with an incision at the anterior axillary line, one with an implant-based reconstruction in a case of an extremely large tumor of 957 grams with no remaining original breast tissue (Figure 4a). In the second case, we also chose the same access to the mammary gland, however with some breast tissue still remaining, we replaced the missing volume with fat harvested from the lateral M. latissimus dorsi region (volume replacement technique without muscle transfer) (Figure 4b). In the third case with a marked ptotis of the affected breast with a massive, enlarged nipple-areola-complex and sufficient remaining breast tissue, we chose a reduction mammaplasty, inferior-pedicled according to Ribeiro in the modification of Rezai (Figure 4c).

\section{Patient-Reported Outcome (PRO)}

To evaluate the patient-reported outcome we used the validated questionnaire Breast $\mathrm{Q}_{\mathrm{TM}}$. A high level of satisfaction with the surgical result was reported by all patients with all three types of reconstruction (Table 1). Psychosocial, as well as physical wellbeing, improved markedly in these young girls after surgery had been performed. Patients are still under constant surveillance. 

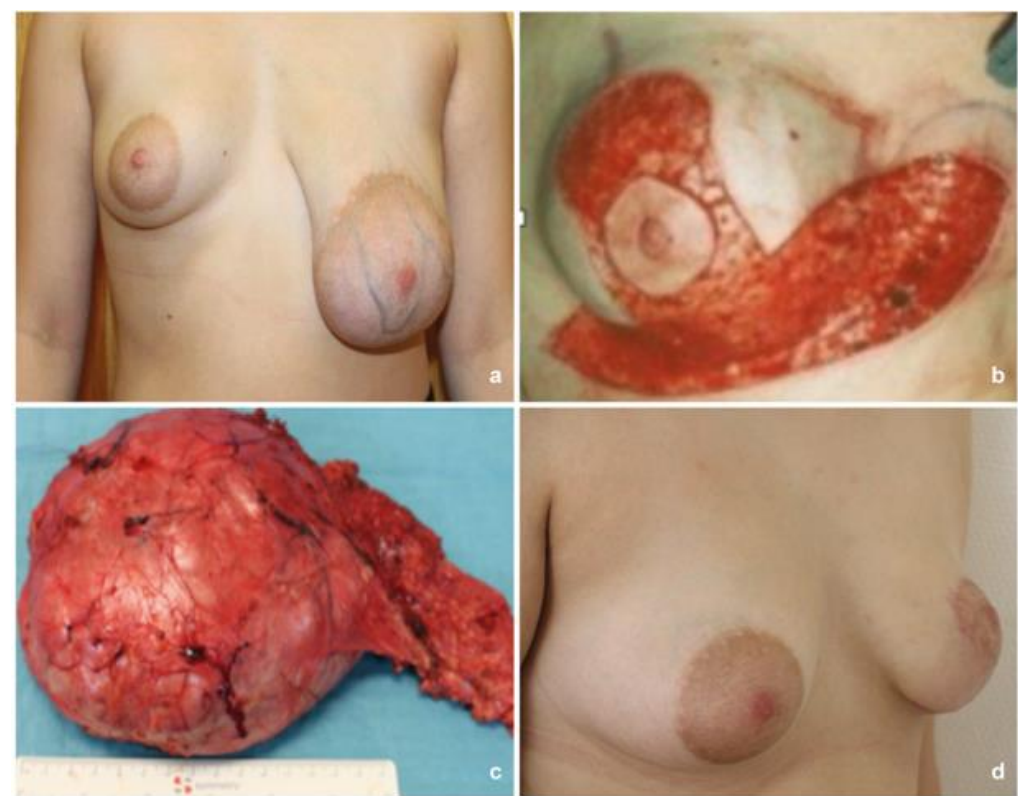

Figure 3: Pre-operative situation of giant fibroadenoma of the left breast: a) marked ptosis of the left breast with massive enlargement of the nipple areola complex. b) Reduction mammaplasty inferior-pedicled according to Ribeiro. c) Removal of 287 grams fibroadenoma with free margins. d) Post-operative result with bilateral B-cup.

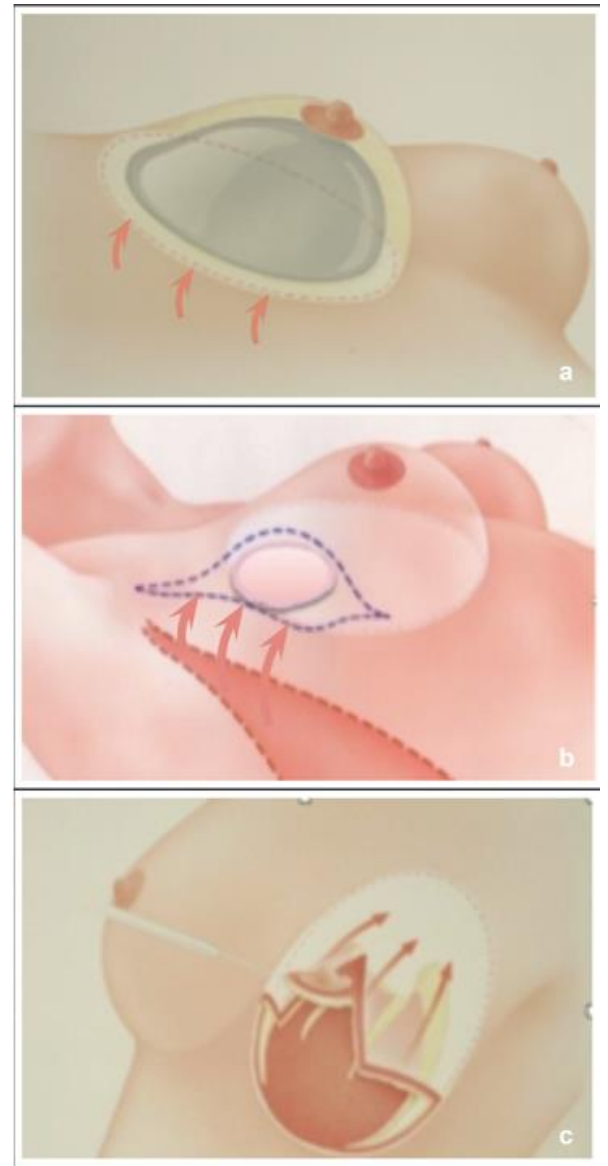

Figure 4: Scar-sparing procedures: a) implant-based reconstruction via the anterior axillary line in extremely large tumors (>500 grams) with no remaining breast tissue after tumor removal (volume replacement technique). b) Autologous reconstruction via the anterior axillary line in medium sized tumors ( $<$ 500 grams) with some remaining breast tissue: fat harvested from the M. latissimus dorsi region (volume replacement technique). c) Autologous reconstruction via reduction mammaplasty in cases of marked ptosis and sufficient remaining breast tissue for re-arrangement (volume displacement technique). 
Table 1: Patient-Reported Outcome (Breast $\mathrm{Q}_{\mathrm{TM}}$ ).

\begin{tabular}{|l|l|l|l|l|l|l|}
\hline & \multicolumn{2}{c|}{ pre-surgical } & \multicolumn{2}{c|}{ post-surgical } \\
\hline & pat 1 & pat 2 & pat 3 & pat 1 & pat 2 & pat 3 \\
\hline satisfaction w breast & 7 & & 4 & 44 & 40 & 37 \\
\hline psychosocial wellbeing & 20 & & 14 & 47 & 50 & 50 \\
\hline physical wellbeing & 10 & & 23 & 13 & 11 & 10 \\
\hline satisfaction w information & - & - & - & 28 & 44 & 40 \\
\hline satisfaction w surgeon & - & - & - & 48 & 48 & 48 \\
\hline satisfaction w med. staff & - & - & - & 28 & 28 & 28 \\
\hline satisfaction w admin staff & - & - & - & 28 & & 28 \\
\hline
\end{tabular}

\section{Discussion}

Breast tumors such cystosarcoma phylloides may exhibit malignant potential and already occur in thelarche. The necessity for surgical intervention interferes with the normal development of the breast, however in certain circumstances, must be performed due to the deformation of the growing breast and the malignant potential of cystosarcoma phylloides. Scars have to be avoided in these young girls because they are still in their premarital and psychologically vulnerable phase. The presumed size of the breast after completion of all Tanner stages of breast development has to be taken into consideration while planning the immediate or deferred reconstruction.

The prevalence of breast masses in adolescent females is 3,25\%, diagnosed with a mean length and width of 2,8 and $1,9 \mathrm{~cm}$ in historical cohorts [6]. Epidemiological data show an annual age-adjusted incidence of breast cancer under the age of 25 years in a US county population by 3.2 per million (95\% confidence interval, 0.1-6.2) [7]. Thus, malignancy is a rare event in teenage breast masses. Hence, some authors argue that observation of pediatric tumors may be sufficient as most of them are of benign origin [2]. However, larger tumors or those with rapid growth or with suspicious features in imaging, warrant surgical excision, especially because the malignant transformation has been reported [8,9]. Adolescents do not often report the growth of a tumor in their breast due to lack of knowledge or shame. The longer the patients postpone their surgical intervention, the greater the defect will be at the time of the decision to undergo surgery. While it has been proposed for giant breast tumors in some case series that they may be handled by simple mastectomy only, for adolescents nowadays, the loss of their breast at such a young age is no longer an option when breast conservation is feasible by autologous or heterologous immediate reconstruction [8].

We report three different types of reconstruction - one implant-based reconstruction and two autologous tissue reconstructions. Our particular approach presented here is a strictly scar-sparing or scar- "hiding" procedure in all three cases because of the extreme young age of the patients. The first case was dealt with an implant-based reconstruction as the removed tissue exceeded to 957 grams, no healthy residual breast tissue was left and the patient was lean. However, the skin envelope has been preserved completely with this procedure and the nipple-areolar complex remained vital. We chose access to the giant tumor through the lateral offspring of the breast near the anterior axillary line - not visible from the front view. Because of the extreme size of the tumor, the surgical intervention resulted almost in a nipple-sparing mastectomy.
The second case with a tumor of 190 grams was subject to the same scarhiding procedure, using an incision at the anterior axillary line, with an autologous reconstruction using fat as a pedicled flap of the M. latissimus dorsi region perfectly filling up the defect caused by the giant fibroadenoma. No transfer of the muscle itself was necessary. The third case was dealt with a reduction mammaplasty as a correction of the massive ptosis of the affected breast with a tumor of 287 grams in a BCup breast. Also here, incision lines were hidden and almost invisible with a vertical incision in the lower part of the breast and at the natural transition of the nipple-areola-complex to the breast. Due to the massive enlargement of the giant tumors, removal of the masses almost came up to a nipple-sparing mastectomy in these giant breast tumors and consequently had to be dealt with such techniques.

Breast-conserving therapy in breast cancer is a legacy of Umberto Veronesi who first conducted prospective trials in the early 70 'ies of the last century [10-14]. Veronesi et al. also reported on a cohort of very young breast cancer patients $<35$ years with acceptable local control with breast-conserving surgery [15]. It is well-known, however that young age $<35$ years is a risk factor for increased local recurrence, as we have published earlier in a cohort of $>1000$ patients with oncoplastic surgery [16].

In the last two centuries, in breast surgery, Langer suggested concentric incision lines whereas Kraissl recommended horizontal incision lines $[17,18]$. Borges et al. described for plastic surgery relaxed skin tension lines (RSTL) as those lines which follow the furrows formed in the state of relaxation of the skin [19]. According to Borges et al., they are nonvisible features of the skin other than wrinkle lines and are rather derived from the act of pinching the skin resulting in furrows and ridges formed by that.

We followed Langer's lines in the first two cases as it was perfectly hiding the scars at the lateral base of the breast close the anterior axillary line. As our proposed scar is extra-mammary, it is not exposed to constant movements of the breast, its gravity, or to greater perpendicular tension which is known for causing dehiscence and being a major cause for stimulating myofibroblasts to produce collagen to broaden the scar and causing keloids [20].

In the third case, however, with a breast ptosis grade 3 according to Regnault - we used a Wise pattern reduction mammaplasty technique, inferior-pedicled according to Ribeiro et al. in the modification of Rezai et al. with a vertical scar in the lower pole of the breast and a periareolar circumcision [21-25]. This allowed a reduction of the excessive skin 
caused by the massive growth of the tumor, and at the same time a reduction of the markedly enlarged nipple-areola-complex to an alignment to the contralateral side. Tarrado $\mathrm{X}$ et al. applied the Strömbeck $(n=9)$ and Lejour technique $(N=1)$ in a group of 10 adolescent girls with 2 cases of them developing hypertrophic scars and some more with wound healing disorders [26]. Kreithen et al. compared the LeJour and the Wise pattern methods of breast reconstruction in a case series of 112 patients [27]. Aesthetic appearance, symmetry, nipple quality, and scarring were assessed using a Likert scale $(10=$ superior, $1=$ poor $)$ by 30 evaluators. Based on the photographic analysis, there was no difference in the aesthetic outcome between the vertical reduction mammaplasty and the inferior pedicle Wise pattern mammaplasty. Additionally, the study indicated that vertical patients with moderate to large reductions have a significantly higher rate of complications when their body mass index is greater than $30 \mathrm{~kg} / \mathrm{m}$. Kulkarni $\mathrm{K}$ et al. reported 60 adolescents undergoing LeJour mammaplasty vs. [28]. Wise pattern mammaplasty, the latter demonstrating statistically significant improvement in NAC contour (Wise $=61 \%$, vertical $=47 \%, \mathrm{P}=0.028$ ) and better overall aesthetic outcome (Wise $=25 \%$, vertical $=17 \%, \mathrm{P}=$ $0.008)$.

In two of the three presented cases of giant breast tumors in our study, a nipple-sparing mastectomy was necessary due to the massive growth of the tumor leaving almost no remaining original breast tissue. There is controversy in literature about the optimal approach for nipple-sparing mastectomy. Incision choices for nipple-sparing mastectomies have been reported by Frey et al. in a cohort of 1027 cases as follows: The majority used an inframammary fold incision (52.9\%), followed by lateral radial incision $(24.4 \%)$, vertical radial incision (13.3\%), Wise pattern $(5 \%)$, previous incisions from breast conserving surgery (BCS) $(2.9 \%)$ and periareolar incision (1.6\%) [29]. In a systematic metaanalysis of Daar DA et al. analysing 9975 nipple-sparing mastectomies, the infra-mammary fold $(37.8 \%)$ and the radial approach $(37.2 \%)$ were the preferred incision choices [30]. The partial and total nipple-areolacomplex (NAC) necrosis rate in this meta-analysis was $4.62 \%$ and 2.49 $\%$, with the highest rates when periareolar approach was used $(18.1 \%)$.

Due to the young age of patients in their thelarche, visible scars on the surface of the breast and partial and total NAC necroses had to be avoided at any price. Chapman-Jackson ED et al. proposed a refinement of the surgical scar of implant-based breast reconstruction with a circumvertical mastectomy incision [31]. In a prospective trial of nipplesparing mastectomies analysing perfusion, complications and patient outcomes, Odom EB et al. discovered - also with the majority of inframammary fold and lateral radial incision - that the patient satisfaction and psychosocial well-being was highest with the lateral radial approach [32].

Implant based reconstruction after mastectomy is reported with and without artificial meshes such as Tiloop Bra Mesh including our own study group [33, 34]. Dermal autografts are the preferred options compared with acellular dermal matrix (ADM) derived from cadaveric skin, because of their potential complications such as seroma and infections and their financial toxicity [35]. Our reconstructions did not require the use of acellular dermal matrices or dermal autografts as the skin envelope remained intact in two cases and was reduced in the third case of a ptotic breast.
Our algorithm is a scar-sparing and scar- "hiding" approach for better patient satisfaction in adolescent girls. This corresponds well with the patient-reported outcome (PRO) in the Breast $\mathrm{Q}_{\mathrm{TM}}$ questionnaire of the two young patients with giant breast tumors who had their incision lines at the lateral base of the breast in the anterior axillary line. The lateral radial incision is clearly visible for the viewer across the skin of the breast at the transition of the outer quadrants, and thus does not seem to be suitable for young girls in their developing phase of their breasts and in their premarital phase.

Our techniques aim at a scar-hiding approach which we achieved with a semi-lunar incision line at the lateral base of the breast - the natural transition of the breast to the thoracic wall. We did not encounter any signs of nipple-areolar-complex necrosis - neither partial nor complete with this technique of incision at the anterior axillary line nor with the reduction mammaplasty according to Ribeiro, modified by Rezai. Carty $\mathrm{NJ}$ et al. have proposed an expectant management policy of fibroadenomas as a significant proportion of them remain static or decrease in size over a 5-year period of time [36]. We did not consider this as appropriate in cases of fibroadenoma, which causes huge deformations of the juvenile breast and massive enlargement of the nipple-areola-complex. Patient satisfaction in validated PRO questionnaires has confirmed that these procedures are very much in line with the patients' expectations.

\section{Conclusion}

We present three types of access to giant breast tumors in adolescence with immediate breast reconstruction. We chose a heterologous reconstruction when no breast tissue was available anymore and patients were very lean $(\mathrm{BMI}<21)$. Autologous tissue-based reconstructions were feasible when such tissue could be harvested from the neighbouring area (volume replacement technique: lateral advancement mammaplasty) or from the breast itself (volume displacement technique). Scars have been avoided in all three techniques in terms of their almost invisibility from front view.

We measured high patient satisfaction with the validated breast surgery questionnaire Breast $\mathrm{Q}_{\text {тм }}$ as patient reported outcomes after each of the 3 procedures. Patients in their adolescence and premarital phase may suffer from severe psychological traumata when conventional incisions in the surface of the breast are performed, due to the uncompleted thelarche and proneness to broad scars in the developing breast, which may lead to difficulties in finding partners and have an undisturbed development of their sexuality. These techniques presented here are suitable to avoid the sequelae with a high score of satisfaction in validated patient-reported outcome questionnaires.

Surgical interventions in gross benign breast disease, e.g., giant cystosarcoma phylloides, PASH-tumors, or fibroadenoma in adolescents, require careful planning of surgery and avoidance of mastectomy or unnecessary scars in the developing breast architecture. Surgical approaches outside the visible surface of the breast recommended by us through the anterior axillary line for surgical removal of the tumor and replacement by thoracic wall advancement mammoplasty or by implants are favourable options in thelarche, especially in cases of young patients who are prone to develop keloids 
and psychological sequelae in their vulnerable phase of the adolescent and pre-marital phase. In cases of macromastia with ptosis, a reduction mammaplasty is an appropriate maneuver that avoids visible scars and allows alignment of the disproportionate size of the areola caused by the tumor.

\section{Conflicts of Interest}

None.

\section{REFERENCES}

1. Jayasinghe Y, Simmons PS (2009) Fibroadenomas in adolescence. Curr Opin Obstet Gynecol 5: 402-406. [Crossref]

2. Omar L, Gleason MK, Pfeifer CM, Sharma P, Kwon JK (2019) Management of Palpable Pediatric Breast Masses With Ultrasound Characteristics of Fibroadenoma: A More Conservative Approach. AJR Am J Roentgenol 212: 450-455. [Crossref]

3. Kennedy RD, Boughey JC (2013) Management of pediatric and adolescent breast masses. Semin Plast Surg 27: 19-22. [Crossref]

4. Johns Hopkins Medicine, Johns Hopkins School of Medicine.

5. Fernandez-Delgado J, Lopez-Pedraza MJ, Blasco JA, AndradasAragones E, Sanchez-Mendez JI et al. (2008) Satisfaction with and psychological impact of immediate and deferred breast reconstruction. Ann Oncol 19: 1430-1434. [Crossref]

6. Neinstein LS, Atkinson J, Diament M (1993) Prevalence and longitudinal study of breast mass in adolescents. J Adolesc Health 14 : 277-281. [Crossref]

7. Simmons PS, Jayasinghe YL, Wold LE, Melton LJ 3rd (2011) Breast carcinoma in young women. Obstet Gynecol 118: 529-536. [Crossref]

8. Liang MI, Ramaswamy B, Patterson CC, McKelvey MT, Gordillo G et al. (2008) Giant breast tumors: surgical management of phyllodes tumors, potential for reconstructive surgery and a review of literature. World J Surg Oncol 6: 117. [Crossref]

9. Makoto A, Miyata S, Nishimura S, Iijima K, Makita M et al. (2011) Malignant transformation of breast fibroadenoma to malignant phyllodes tumor: long-term outcome of 36 malignant phyllodes tumors. Breast Cancer 18: 268-272. [Crossref]

10. Veronesi U, Banfi A, Saccozzi R, Salvadori B, Zucali R et al. (1977) Conservative treatment of breast cancer. A trial in progress at the Cancer Institute of Milan. Cancer 39: 2822-2826. [Crossref]

11. Veronesi U, Saccozzi R, Vecchio MD, Banfi A, Clemente C et al. (1981) Comparing radical mastectomy with quadrantectomy, axillary dissection, and radiotherapy in patients with small cancers of the breast. N Engl J Med 305: 6-11. [Crossref]

12. Veronesi U, Volterrani F, Luini A, Saccozzi R, Vecchio MD et al. (1990) Quadrantectomy versus lumpectomy for small size breast cancer. Eur J Cancer 26: 671-673. [Crossref]

13. Veronesi U, Zurrida S (2009) Preserving life and conserving the breast. Lancet Oncol 10: 736. [Crossref]

14. Veronesi U, Cascinelli N, Mariani L, Greco M, Saccozzi R et al. (2002) Twenty-year follow-up of a randomized study comparing breastconserving surgery with radical mastectomy for early breast cancer. $N$ Engl J Med 347: 1227-1232. [Crossref]
15. Gentilini O, Botteri E, Rotmensz N, Toesca A, De Oliveira $\mathrm{H}$ et al. (2010) Breast-conserving surgery in 201 very young patients ( <35 years). Breast 19: 55-58. [Crossref]

16. Rezai M, Kellersmann S, Knispel S, Lax H, Kimmig R et al. (2015) Translating the concept of intrinsic subtypes into an oncoplastic cohort of more than 1000 patients - predictors of recurrence and survival. Breast 24: 384-390. [Crossref]

17. Langer K (1861) Zur Anatomie und Physiologie der Haut. Über die Spaltbarkeit der Cutis. Sitzungsbericht der Mathematischnaturwissenschaftlichen Klasse der Wiener Kaiserlichen Akademie der Wissenschaften Abt. 44: 19-46.

18. Kraissl CJ (1946) The selection of appropriate lines for elective surgical incisions. Plast Reconst Surg 8:1-28. [Crossref]

19. Borges AF (1984) Relaxed skin tension lines (RSTL) versus other skin lines. Plast Reconstr Surg 73: 144-150. [Crossref]

20. Van de Water L, Varney S, Tomasek JJ (2013) Mechanoregulation of the Myofibroblast in Wound Contraction, Scarring, and Fibrosis: Opportunities for New Therapeutic Intervention. Adv Wound Care (New Rochelle) 2: 122-141. [Crossref]

21. Regnault P (1976) Breast ptosis. Definition and treatment. Clin Plast Surg 3: 193-203. [Crossref]

22. Wise RJ (1946) A preliminary report on a method of planning the mammaplasty. Plast Reconstr Surg 17: 367-375. [Crossref]

23. Ribeiro L (1975) A new technique for reduction mammaplasty. Plast Reconstr Surg 55: 330-334. [Crossref]

24. Ribeiro L, Accorsi A Jr, Buss A, Marcal-Pessoa M (2002) Creation and evolution of 30 years of the inferior pedicle in reduction mammaplasties. Plast Reconstr Surg 110: 960-970. [Crossref]

25. Rezai M, Kern P, Kraemer S (2013) Oncoplastic Reduction Mammaplasty: Incision Patterns, Safety Issues and Plasticity. in: Urban C, Rietjens M (Editors): Oncoplastic and Reconstructive Breast Surgery, Springer, Mailand.

26. Tarrado X, Parri FJ, Sarget R, Sancho MA, Morales L (2002) Mammaplasty in adolescent girls. Cir Pediatr 15: 25-28. [Crossref]

27. Kreithen J, Caffee H, Rosenberg J, Chin G, Clayman M et al. (2005) A comparison of the LeJour and Wise pattern methods of breast reduction. Ann Plast Surg 54: 236-241. [Crossref]

28. Kulkarni K, Egro FM, Kenny EM, Stavros AG, Grundwaldt LJ (2019) Reduction Mammaplasty in Adolescents: A Comparison of Wise and Vertical Incision Patterns. Plast Reconstr Surg Glob Open 7: e2516. [Crossref]

29. Frey JD, Salibian AA, Levine JP, Karp NS, Choi M (2018) Incision Choices in Nipple-Sparing Mastectomy: A Comparative Analysis of Outcomes and Evolution of a Clinical Algorithm. Plast Reconstr Surg 142: 826e-835e. [Crossref]

30. Daar DA, Abdou SA, Rosario L, Rifkin WJ, Santos PJ et al. (2019) Is There a Preferred Incision Location for Nipple-Sparing Mastectomy? A Systematic Review and Meta-Analysis. Plast Reconstr Surg 143: 906e-919e. [Crossref]

31. Chapman-Jackson ED, Griner D, Brzezienski MA (2014) Circumvertical mastectomy incision: refinement in the surgical scar of implant-based breast reconstruction. Ann Plast Surg 72: S97-S102. [Crossref]

32. Odom EB, Parikh RP, Um G, Kantola SW, Cyr AE et al. (2018) NippleSparing Mastectomy Incisions for Cancer Extirpation Prospective Cohort Trial: Perfusion, Complications, and Patient Outcomes. Plast Reconstr Surg 142: 13-26. [Crossref] 
33. Chen G, Zhang Y, Xue J, Zhu X, Liu C et al. (2019) Surgical Outcomes of Implant-based Breast Reconstruction Using TiLoop Bra Mesh Combined With Pectoralis Major Disconnection. Ann Plast Surg 83: 396-400. [Crossref]

34. Rezai M, Strauß S, Kimmig R, Kern P (2016) Risk-reducing, conservative mastectomy-analysis of surgical outcome and quality of life in 272 implant-based reconstructions using TiLoop(®) Bra versus autologous corial flaps. Gland Surg 5: 1-8. [Crossref]
35. Davis C, Boyd C, Mateo de Acosta Andino DA, Kumbla PA, Sanchez RJ et al. (2020) Dermal Autografts in Breast Reconstruction: A Review of Past and Current Trends. Ann Plast Surg 84: 618-622. [Crossref]

36. Carty NJ, Carter C, Rubin C, Ravichandran D, Royle GT et al. (1995) Management of fibroadenoma of the breast. Ann R Coll Surg Engl 77: 127-130. [Crossref] 